\title{
Numerical modeling and assessment of natural gas pipeline separation in China: the data from Henan Province
}

\author{
Jian-zhong Xiao ${ }^{1,2} \cdot$ Wei-cheng Kong ${ }^{1,2} \cdot$ Xiao-lin Wang $^{1,2} \cdot$ Ming Li $^{1,2}$
}

Received: 10 October 2018 / Published online: 4 November 2019

(c) The Author(s) 2019

\begin{abstract}
China's natural gas market is focusing on price reform and aims to reconstruct vertically integrated industrial chains in the future. Based on the mixed complementarity problem model of gas markets with nodes in Henan Province, China, as an example, this paper applies numerical modeling to simulate the effects of social welfare and equilibrium prices on nodes in two scenarios: pipeline integration and pipeline separation. The findings reveal the following: (1) Pipeline separation yields greater overall social welfare than pipeline integration, with the welfare shifting from gas producers to consumption markets. (2) Pipeline separation lowers the equilibrium consumption prices by driving competition among gas supply sources. (3) Pipeline separation will increase the contribution of natural gas to primary energy.
\end{abstract}

Keywords Natural gas $\cdot$ Market equilibrium $\cdot$ Mixed complementarity problem $\cdot$ Pipeline separation $\cdot$ Pipeline integration

\section{Introduction}

China has become one of the world's largest natural gas consumers and importers, with the amount of imported pipeline gas and liquefied natural gas (LNG) reaching one-quarter of Chinese natural gas consumption and with increasing quantities of domestic gas production from areas far from demand centers. One key energy policy objective in China is increasing the contribution of natural gas to the energy mix (China National Energy Administration 2014). The Chinese government has introduced a series of policies to encourage domestic and international gas supply expansion and efficient gas use, including a pilot natural gas pricing reform and longdistance pipeline reform. Currently, China has established gas pipeline networks covering the entire country, and the total long-distance pipeline length in China reached 77.0 thousand kilometers at the end of 2017 (Electronics and

Edited by Xiu-Qin Zhu

Jian-zhong Xiao

xjianzhong@cug.edu.cn

1 School of Economics and Management, China University of Geosciences, Wuhan 430074, Hubei, China

2 Resources and Environment Economic Research Center, China University of Geosciences, Wuhan 430074, Hubei, China
Telecommunications Research Institute 2018). According to China's oil and gas pipeline medium- and long-term network plan issued in 2017, the natural gas long-distance pipeline is expected to exceed 104 thousand kilometers by 2020 and 163 thousand kilometers by 2025, with an annual growth rate of 9.8\% (China National Development and Reform Commission 2017).

Traditionally, the natural gas pipeline network in China is dominated by three state-owned companies: China National Petroleum Corporation (CNPC), China Petrochemical Corporation (SINOPEC) and China National Offshore Oil Corporation (CNOOC) (Xu et al. 2017). Recently, it was proposed that energy companies provide more transparency regarding their pipeline operations, including selling assets to nonstate investors and owners allowing fair access to their networks for all producers and consumers.

In this respect, the natural gas market structure in China is undergoing significant change. However, in the process of pipeline reform, an important issue is whether ownership unbundling and/or mandatory separation is a feasible policy initiative. Studies have shown that ownership unbundling increases social welfare by fostering competition for downstream and upstream markets, thus reducing the risk of vertical foreclosure and lower retail prices (Laffont and Tirole 1994). Similar research on China suggests that ownership unbundling is more conducive to promoting the efficiency of natural gas transmission compared with a 
vertically integrated operation system (Dong et al. 2018). In contrast, Lewis (2007) argues that ownership unbundling does not seem feasible because unbundling gas pipelines implies completely relinquishing control of relevant assets at national and local levels. Such unbundling and its implications have proven to involve a difficult political process in EU and US gas market liberalization (Xu et al. 2017). Thus, in this study, we agree that ownership unbundling is not a feasible solution.

Certain studies on gas pipeline separation reveal the importance of fair access (David and Percebois 2004; Vazquez et al. 2012). Experiences in liberalized markets indicate that the exclusivity (i.e., that it is relatively easy to physically exclude individuals from using gas infrastructure) and subtractability (i.e., the use of network infrastructure decreases the available capacity) of private pipelines are a source of severe transaction costs (Hallack and Vazquez 2014).

Based on these considerations, the current market structure in China requires further research. The numerical simulation model developed in this paper, termed CNGASMOD, represents a contribution to this research. It simulates strategic behavior within the demand and supply structures, particularly gas pipelines. The static version of the model presented in the paper studies interaction behavior among market agents by analyzing the market-clearing price and social welfare as a mixed complementarity problem. The paper is structured as follows: Sect. 2 presents a review of the literature. Section 3 describes the modeling and scenario setting for the natural gas market and is followed by an analysis of results in Sec. 4. Section 5 presents conclusions and policy suggestions.

\section{Literature review}

The main purpose of regional natural gas market modeling is to analyze the impact of policy, external shock and infrastructure developments on markets. Because of the success of natural gas market reform in the USA and Europe, many scholars have studied these two markets. For the US natural gas market, based on the Stoner's (1969) research, O'Neill et al. (1979) provided a model consisting of several objective functions with a set of linear and nonlinear constraints. Subsequently, to determine the optimal method to reassign the available gas supply to consumers under different scenarios, such as low pipeline capacity and supply disruption, several researchers have developed models based on their predecessors' research (Gabriel et al. 2005; Growitsch et al. 2014). The National Energy Modeling System (NEMS), led by the Energy Information Administration (EIA), contains a separate subsystem for modeling the US natural gas market, the Natural Gas Transmission and Distribution Module
(NGTDM) (Gabriel et al. 2001). Gabriel et al. (2005) noted the existence of Nash-Cournot competition in the North American natural gas market and used the mixed complementarity problem (MCP) to assess the impact of market power.

For the European natural gas market, Golombek et al. (1995) used a numerical model to examine the long-term impact of a radical liberalization of the West European natural gas markets and found that the process of liberalization can increase upstream competition and economic welfare. The EUGAS model developed by Perner and Seeliger (2004) is used to study the optimization problem of the long-term supply in the European gas market. The numerical EUGAS model relies on linear programming (LP). Boots et al. (2004) constructed the GASTALE model from the perspective of successive oligopoly. In a further development of GASTALE, Egging and Gabriel (2006), Egging and Holz (2016) added features such as demand seasonality, a storage sector and transmission pipeline capacities. The agents of this model include producers, a transmission system operator and storage operators, and market power exertion is accommodated in the interaction between producers and demand sectors.

Other models for the European market include NATGAS (Zwart and Mulder 2006) and GASMOD (Holz et al. 2008). The NATGAS model (Zwart 2009) analyzes the strategic interactions between upstream producers and downstream arbitragers, simulates liquefied natural gas (LNG) price variation under different scenarios and studies changes in equilibrium prices and import volumes. Traditionally, the GASMOD model is used for numerical simulations of three market scenarios: Cournot competition in both (i.e., upstream and downstream) markets, perfect competition in both markets and Cournot competition in the upstream market with a downstream market in perfect competition.

The EU gas model is unique in its combination of a high level of detail regarding the actors in the natural gas markets and the representation of market power according to the Nash-Cournot setting. Thus, a shift can be observed to more advanced modeling approaches, such as mixed complementarity problems, following the preliminary study by Gabriel et al. (2009). Egging et al. (2010) further developed the model, creating the first version of the World Gas Model (WGM). This model covered the entire world and multiple periods while providing a detailed representation of the LNG supply chain and facilitating endogenous infrastructure expansions. Another example is the Gas Market Model (COLUMBUS) developed by Hecking and Panke (2012). The distinctive feature of the WGM and COLUMBUS models is that they explicitly model the market power of agents.

Because of the complexity of the interrelations in the global gas market, Growitsch et al. (2014) use a programmed MCP equilibrium model and simulate the blockage of LNG 
flows through the Strait of Hormuz. This approach enables consideration of the oligopolistic nature and asymmetry of the gas supply. Devine et al. (2016) present a new approach for solving energy market equilibria that extends the classical Nash-Cournot approach to solving stochastic MCPs. $\mathrm{Xu}$ et al. (2017) investigate third-party access regulatory issues in China's natural gas industry applying an oligopolistic equilibrium model based on the mixed complementarity problem.

Table 1 provides an overview of the equilibrium natural gas market models published in the public domain.

The cited literature illustrates that the bottom-up modeling method of MCP approaches can well depict the structural features of the natural gas market and the behaviors of players within nodes. Thus, such approaches are widely applied in research on the natural gas markets in Britain, the USA and the European Union.

Most of the literature creates objective functions and constraint conditions for each market player in the framework of MCP, derives the equivalent Karush-Kuhn-Tucker (KKT) conditions and uses GAMS as a system programming tool. The literature has focused on Western economies, whereas the modeling of China's natural gas market is comparatively limited. This paper examines the regional natural gas market in Henan Province in Central China using an MCP model to simulate the natural gas market equilibrium.

The contributions of this research are threefold: (1) This study is potentially the first market modeling to address the interaction between market agents and equilibrium in the Chinese natural gas market. (2) The impact of China's natural

Table 1 Overview of natural gas model characteristics

\begin{tabular}{llllc}
\hline Model & Type & Coverage & Market power & Nodes \\
\hline NEMS & LP & USA, CAN & No & 15 \\
GASMOD & MCP & EU & Yes & 6 \\
GASTALE & MCP & EU & Yes & 19 \\
NATGAS & LP & EU & No & 11 \\
WGM & MCP & World & Yes & 41 \\
COLUMBUS & MCP & World & Yes & 215 \\
\hline
\end{tabular}

gas market restructuring on node price and social welfare is described. (3) This study also serves as an additional reference for market players, including policymakers, as they develop their market liberalization policies.

\section{Equilibrium model for the Chinese natural gas market}

We now establish the KKT conditions in terms of agent behavior in a monopoly. This interpretation enables one to formulate the different assumptions of imperfect competition. In this paper, these assumptions refer to gas supply fields, oil-gas companies, distributors, pipeline operators and gas-using cities in Henan Province. During the modeling, producers and consumption markets are nodes connected with natural gas pipelines.

\subsection{Scenario 1: Pipeline integration}

A pipeline network is currently integrated in China's natural gas industry, whereby three state-owned companies manage the transportation and sale of pipelines. In this scenario, the players involved in the current market are producers, distributors and gas-using cities. The logical structure of market players is shown in Fig. 1.

According to the characteristics of each player, the equilibrium model is as follows.

\subsubsection{Producer behavior}

Producers sell natural gas to distributors for profit. The producers' objective function is profit maximization, and the corresponding constraint conditions are as follows:

$$
\begin{aligned}
& \max _{q_{n \rightarrow p}}\left(p_{n \rightarrow p}-c_{n}\right) \cdot q_{n \rightarrow p} \\
& \text { s.t. } q_{n \rightarrow p} \geq 0 \text {; } \\
& q_{n \rightarrow p} \leq w_{n} \perp \alpha_{w}
\end{aligned}
$$

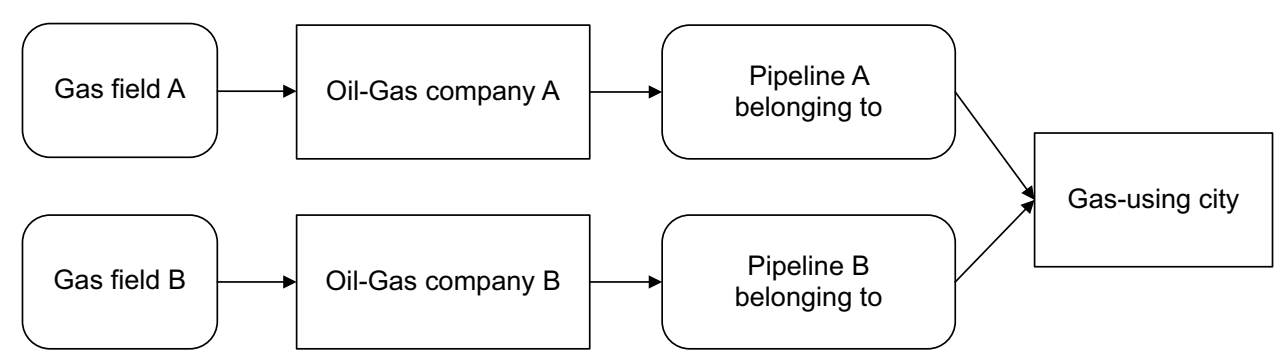

Fig. 1 Logical structure of market players in the integrated pipeline transport scenario 
where $p_{n \rightarrow p}$ is the prices at which distributors purchase natural gas, $c_{n}$ denotes the marginal exploitation costs of natural gas production, $q_{n \rightarrow p}$ represents the amount of natural gas producers sell to distributors and $w_{n}$ is the capacity of the gas fields, that is, their capacity constraints. $\alpha_{w}$ is the shadow prices under the gas field capacity constraints.

\subsubsection{Natural gas distributor behavior}

Natural gas transportation and sales are the main businesses for distributors, who obtain profits by purchasing gas at lower prices and selling it to gas-using cities at higher prices. They use their own pipelines during transportation, and rents are required when the pipelines of other companies are used. Similarly, others pay rents when borrowing the pipelines of the distributors. Natural gas distributors aim for profit maximization. The corresponding objective function and constraint conditions are as follows:

$$
\begin{aligned}
& \max _{\substack{q_{p \rightarrow n} \\
q_{n \rightarrow p}}}\left(\sum_{n} p_{c} q_{p \rightarrow n}-\sum_{n} p_{n \rightarrow p} \cdot \operatorname{purch}_{p \leftarrow n}-\sum \text { flow }_{n m} \cdot \mathrm{TC}_{n m}\right) \\
& \text { flow }_{n m} \\
& \text { s.t. } \text { purch }_{p \leftarrow n}+\sum_{m} \text { flow }_{n m}=q_{p \rightarrow n}+\sum_{m} \text { flow }_{n m} \perp \varphi^{n} \\
& \\
& q_{p \rightarrow n} \geq 0 \\
& \quad \text { flow }_{n m} \geq 0 \\
& \quad \text { flow }_{n m} \leq \overline{\text { flow }_{n m}} \perp \alpha^{\text {pipe }}
\end{aligned}
$$

where $q_{p \rightarrow n}$ is the amount of natural gas distributors sell to downstream gas-using cities, $p_{c}$ is the final consumer price in gas-using cities, flow $_{n m}$ refers to the natural gas flow from node $n$ to node $m$, $\operatorname{purch}_{p \leftarrow n}$ denotes the amount of natural gas distributor $p$ purchases from producer $n, \mathrm{TC}_{n m}$ is the marginal transport costs of natural gas, $\varphi^{n}$ is the dual variable of flow conservation and $\alpha^{\text {pipe }}$ represents the shadow prices under the transportation constraints.

\subsubsection{Consumer behavior}

Consumers buy natural gas from natural gas distributors. This paper examines the market's response to price from an industrial perspective, with a focus on the reconstruction of vertically integrated industrial chains and thus regardless of substitution between different energy commodities; therefore, we simplify the consumer to construct a linear function, and other models also assume demand to be a linear function (Zwart 2009; Xu et al. 2017). In addition, the demand functions for each gas-using city are assumed to be simple linear functions:

$p_{c}=a+b \cdot \sum_{p} q_{p \rightarrow n}$

Equation (3) shows the supply-demand balance between distributors and gas-using cities, where $a$ and $b$ are the intercept and elasticity of the demand functions, respectively.

\subsubsection{Market-clearing conditions}

As an indispensable part of an MCP model, market-clearing conditions are essentially the balance between supply and demand. They are stated as follows:

purch $_{p \leftarrow n}=q_{p \rightarrow n} \perp p_{n \rightarrow p}$

Equation (4) shows the supply-demand balance between producers and distributors.

\subsection{Scenario 2: Pipeline separation}

Independent pipeline operators originate through the asset stripping of natural gas pipelines subordinate to oil-gas companies. After division, a single national pipeline company, or several regional companies, can be established. Under these circumstances, oil-gas companies are only responsible for sales. Transportation is assigned to independent pipeline operators. The logical structure of the market players is shown in Fig. 2.

Pipeline separation directly affects the objective functions of distributors with integrated pipeline transportation. In the equilibrium model, the objective functions and constraint

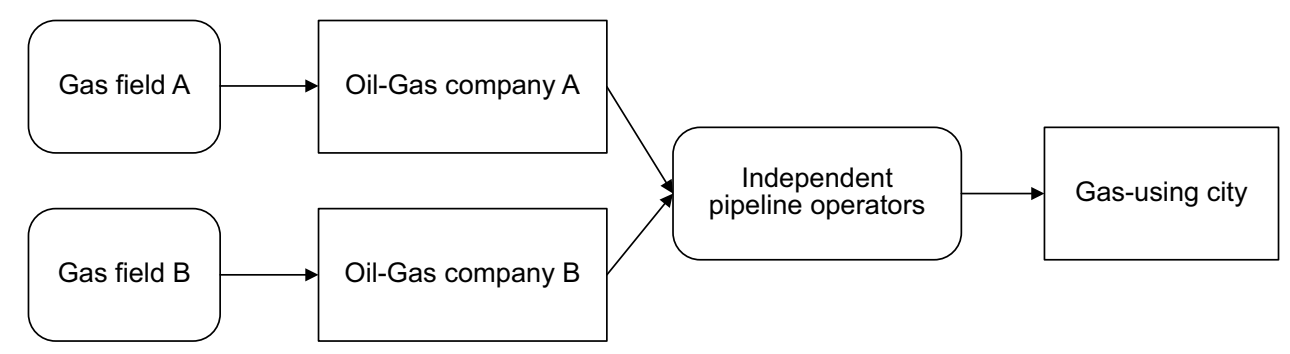

Fig. 2 Logical structure of the market players in the independent pipelines scenario 
conditions of the producers (Eq. 1) and gas-using cities (Eq. 3) exhibit no variation with the addition of pipeline operators. The equilibrium model is as follows.

\subsubsection{Natural gas distributors}

Oil-gas companies obtain profits by purchasing gas from producers at lower prices and selling it to independent pipeline operators at higher prices. However, they must pay pipeline rents during the transportation process. The profit maximization function and constraint conditions of natural gas distributors are as follows:

$$
\begin{aligned}
\max _{x_{p n m}} & \left(x_{p n m} \cdot p_{c}-x_{p n m} \cdot p_{n \rightarrow p}-\sum_{n m}\left(\text { tfee }_{n m} \cdot \text { flow }_{n m}\right)\right) \\
\text { flow }_{n m} & \\
\text { s.t. } & \text { flow }_{n m} \geq 0 \\
& x_{p n m} \geq 0 \\
& \left\lfloor\sum_{m \neq n} x_{p n m}-\sum_{m \neq n} \text { flow }_{n m}\right\rfloor+\left\lfloor\sum_{m \neq n} \text { flow }_{n m}-\sum_{m \neq n} x_{p n m}\right\rfloor=0
\end{aligned}
$$

where tfee ${ }_{n m}$ represents the transport fees paid to independent pipeline operators by distributors, $x_{p n m}$ is the amount of natural gas distributors purchase from producers and sell to gas-using cities and flow $_{n m}$ is the gas flow between nodes $n$ and $m$.

\subsubsection{Independent pipeline operators}

Independent pipeline operators seek to obtain a reasonable profit by selling the right to use their pipeline networks. The profit maximization function and constraint conditions are as follows:

$$
\begin{aligned}
\max _{Z_{n m}}\left(\mathrm{tfee}_{n m} \cdot Z_{n m}-\mathrm{TC}_{n m} \cdot Z_{n m}\right) \\
\text { s.t. } Z_{n m} \leq \overline{\text { flow }_{n m}}\left(\alpha^{\mathrm{pipe}}\right) \\
\quad Z_{n m} \geq 0
\end{aligned}
$$

\section{Data and results}

\subsection{Data}

Prior to 2011, the pricing mechanism for the natural gas market was cost-plus pricing. The Chinese government determined the price at natural gas terminals based on the average cost of the natural gas producers plus a reasonable profit rate. Cost-plus pricing played a positive role in increasing the contribution of natural gas to the energy mix and in pipeline network construction. However, in this method, supply and demand are ignored, and the price of natural gas is relatively lower than other energy resources, resulting in excessive development of the natural gas consumer market. With the development of pipeline networks, it has become increasingly difficult to distinguish natural gas flows between gas fields and gas-using cities, meaning it is difficult to determine the price of natural gas in different gasusing cities. In 2011, the National Development and Reform Commission of the People's Republic of China piloted netback pricing for natural gas in Guangxi and Guangdong Provinces. Natural gas prices began to be linked to alternative energy prices and to be promoted nationwide in 2013 . This policy will make it easier to calculate the consumer price of natural gas. Therefore, in this paper, 2010 and 2015 are selected as research time points.

(1) Upstream production and cost

Domestic upstream gas production has a long history of oligopoly and is currently monopolized by three dominant companies: China National Petroleum Corporation (CNPC), China Petroleum and Chemical Corporation (SINPEC) and China National Offshore Oil Corporation (CNOOC). Notably, the first two have $90 \%$ of the supply share. Since data on the cost, price and volume of imported natural gas are difficult to obtain and the companies themselves do not make such data public, a simplified approach was adopted during the research.

Henan mainly purchases gas from diverse sources, such as Lunnan in the Tarim Basin, Yulin and the Zhongyuan Oil Field that belongs to CNPC and Horgos from Turkmen. Here, the analyzed data on gas field output were drawn from CNPC annual reports. The production costs are calculated using cost-plus pricing. The ex-factory price of natural gas is the production cost plus a reasonable profit. Considering the reasonable profit of $12 \%$ allowed by oil-gas industrial countries, the production costs can be indirectly obtained by multiplying the ex-factory prices disclosed by regulatory departments by $88 \%$. The data on the ex-factory prices of natural gas are adopted from the Notice on Natural Gas Prices in West-East Transmission by the China National Development and Reform Commission (CNDRC) and the Adjustment Table of Benchmark Ex-factory/First-Station Prices of Domestic Onshore Natural Gas of 2010. Table 2 lists gas field production, wellhead prices and production costs.

(2) Natural gas pipelines

Located in Central China, Henan Province is an important region because of the convergence that occurs there of critical long-distance pipelines, such as the First West-East Gas Pipeline, the Second West-East Gas Pipeline, the Third West-East Gas Pipeline, the Sichuan-East Branch Gas Pipeline and the Yima Pipeline. These pipelines provide Henan Province with imported gas from Middle Asia and domestic gas, which flows to the main consumer region, including 
Table 2 Domestic production quantities, prices and costs for domestic producers in 2010/2015

\begin{tabular}{llll}
\hline & Output, $10^{9} \mathrm{~m}^{3}$ & $\begin{array}{l}\text { Wellhead } \\
\text { price, CNY/ } \\
\mathrm{m}^{3}\end{array}$ & $\begin{array}{l}\text { Production } \\
\text { cost, CNY/ } \\
\mathrm{m}^{3}\end{array}$ \\
\hline Lunnan & $18.4 / 25$ & $0.48 / 0.79$ & $0.49 / 0.695$ \\
Horgos & $35 / 31.1$ & $2.27 / 2.27$ & $2 / 2$ \\
Yulin & $2.4 / 4$ & $0.71 / 0.94$ & $0.62 / 0.827$ \\
$\begin{array}{l}\text { Zhongyuan Oil Field } \\
\text { (Dongpu Depres- } \\
\text { sion) }\end{array}$ & $0.4 / 0.38$ & $0.71 / 0.94$ & $0.62 / 0.827$ \\
\hline
\end{tabular}

Sources: Notice on Natural Gas Prices in West-East Transmission by the CNDRC; Adjustment Table of Benchmark Ex-factory/First-Station Prices of Domestic Onshore Natural Gas

South and East China. The data on contract quantity, the pipeline capacity of oil-gas companies and Henan Province in 2010 and 2015 are from the Outline of Natural Gas Development and Utilization Plan for Henan Province
(2011-2020). Similar to the production cost of gas fields, the pipeline transport fee equals $88 \%$ of the prices issued by CNDRC.

(3) Gas-demand cities

Gas-demand cities can be grouped as nodes in accordance with the following three requirements. First, the pipelines enter the first city located in Henan Province. Second, the node cities are the intersections between trunk lines and branch lines. Finally, the consumption cities receive the product. As required, the nodes selected in the natural gas market in Henan Province include Boai, Xuedian, Pingdingshan, Sanmenxia, Kaifeng, Huaiyang, Anyang and Qingfeng (Fig. 3). Table 3 lists gas-demand quantities, price and elasticity for nodes in 2015.

\subsection{Simulation results}

As discussed, we assume that China's natural gas market is an oligopolistic market. Thus, this paper simulates scenarios of imperfect competition in upstream markets. Although the scenario of pipeline separation seems realistic, the

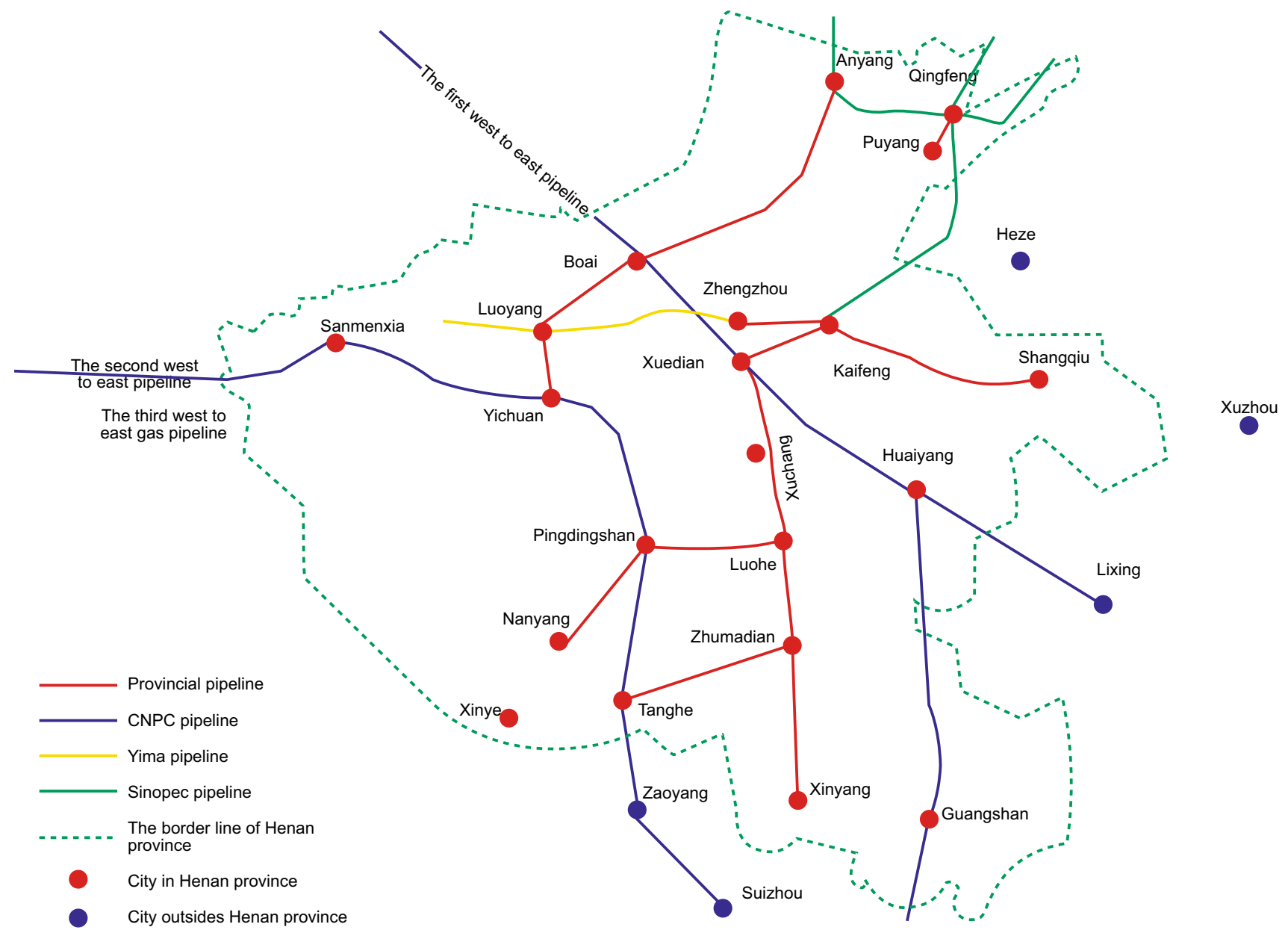

Fig. 3 Gas pipelines and nodes in the regional natural gas market, Henan (China) 
Table 3 Gas-demand quantities, price and elasticity for nodes in 2015 (for brevity, the elastic calculation process is omitted)

\begin{tabular}{llll}
\hline & $\begin{array}{l}\text { Gas consump- } \\
\text { tion, } 10^{4} \mathrm{~m}^{3}\end{array}$ & Demand elasticity & $\begin{array}{l}\text { Gas price, } \\
\mathrm{CNY} / \mathrm{m}^{3}\end{array}$ \\
\hline Boai & 18794.35 & -0.134 & 2.05 \\
Xuedian & 3719 & -0.048 & 2.25 \\
Sanmenxia & 10861.4 & -1.344 & 2.19 \\
Pingdingshan & 9366 & -0.29 & 2.19 \\
Kaifeng & 5362 & -0.333 & 2.25 \\
Anyang & 19359 & -0.297 & 2.24 \\
Huaiyang & 6852.6 & -0.07 & 2.14 \\
Qingfeng & 5781.45 & -0.2 & 2.1 \\
\hline
\end{tabular}

The consumption market does not distinguish whether the gas is used for industry, power generation or households. The gas consumption amount is the total gas demand, and the demand elasticity is calculated based on the demand function

unbundling of the China's natural gas sector is assumed to lead to a competitive market in the future.

\subsubsection{Equilibrium revenue for market agents}

(1) Upstream producers

As discussed in Introduction, China's gas producers are state-owned enterprises. For them, attaining public targets is more important than profit maximization and supply security. According to the results, we compared the earnings of companies at the same time points in different scenarios (Fig. 4).

As shown in Fig. 4, under the same scenario, two companies had far more earnings in 2015 than 2010, and CNPC displayed more significant growth. In the case of the integrated pipeline scenario, the earnings of CNPC and Sinopec increase by 1.93 times and 1.8 times, respectively. However, in the comparison (i.e., pipeline separation) scenario, the corresponding profit variations were 0.20 times and 0.13 times. The main reason for these results is that CNPC owns the West-East Gas Pipelines, which supply natural gas to Henan Province. The amount of gas supplied by CNPC was nearly $3.5423 \mathrm{bcms}$ in 2010 and increased to $13.1215 \mathrm{bcms}$ in 2015. Sinopec supplied $1.0733 \mathrm{bcms}$ in 2010 and $2.5612 \mathrm{bcms}$ in 2015. In 2010, Sinopec accounted for $17.23 \%$ of the gas supply market in Henan Province, and for all earnings growth in 2015, its market share decreased to $9.7 \%$. If the market structure is assumed to consist of an oligopoly of upstream gas producers, price discrimination by oil and gas producers is allowed, and these producers will collect a larger share of the margins on end-use prices.

Compared across the two scenarios, both companies exhibit a significant decrease in earnings, particularly CNPC: The earnings of CNPC and Sinopec decrease by $79.71 \%$ and $57.27 \%$, respectively. In 2015 , the corresponding figures were $89.94 \%$ and $78.95 \%$. The decrease can be attributed to the deregulation of the right to pipeline transportation and the mandatory separation of pipelines, according to which oil-gas companies no longer own pipelines and must pay independent pipeline operators transportation fees. In Henan Province, CNPC owned the First West-East Gas Pipeline, the Second West-East Gas Pipeline and other cross-country pipelines, which together extend $1407.6 \mathrm{~km}$, approximately 2.8 times the length of Sinopec's system. In the case of unbundling the transmission pipeline, when independent pipeline companies are separated, the result will be weaker market power and a sharp decrease in earnings.

(2) Independent pipeline operators

The earnings of independent pipeline operators reflect the transfer of profits from integrated companies to independent pipeline operators along the industrial chain. These earnings can potentially be explained by the regime of legal
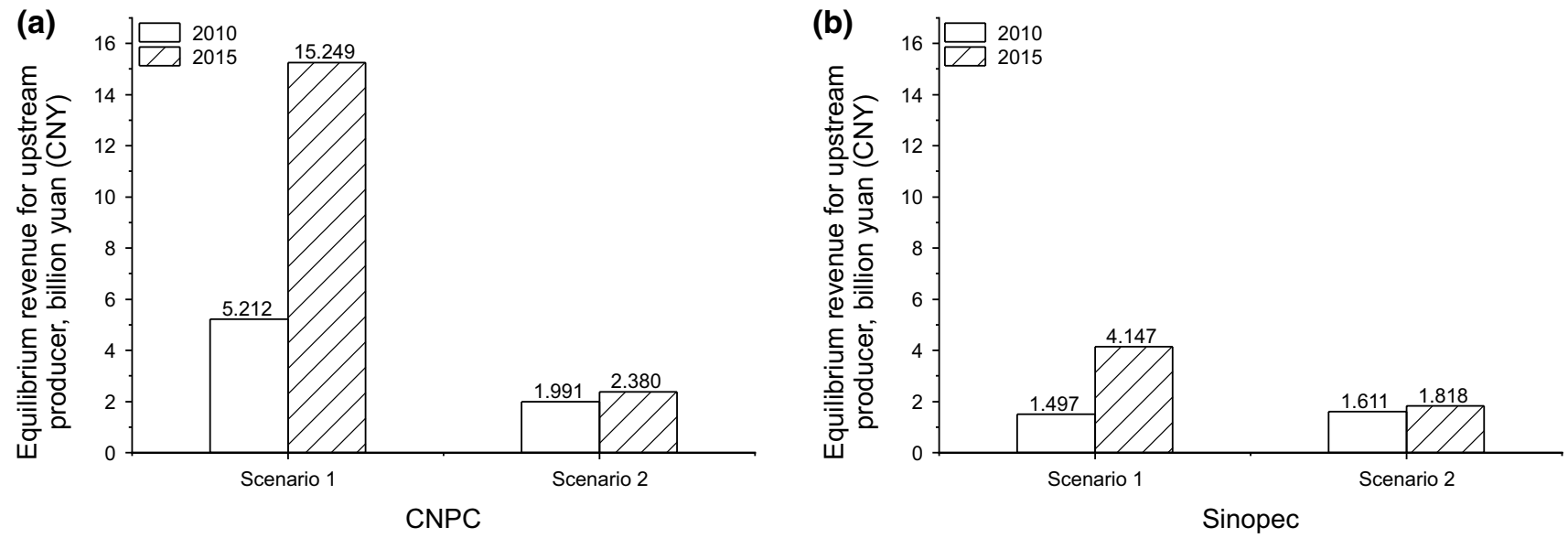

Fig. 4 Earnings of gas producers under different scenarios in 2010 and 2015 
regulation, according to which the transmission and incumbent firms are legally separated but part of the same economic corporation. That is, the firms strategically maximize the joint profits of the corporative group. Independent pipeline operators optimize the transportation capacity of the entire natural gas pipeline network and reduce the scarcity of pipeline network resources. The consumer can choose the lowest price among the multiple gas source competitors, and the producers can choose the route with the lowest transportation cost.

(3) Downstream market

Next, we compare the changes in earnings of the downstream market under the two scenarios. As shown in Fig. 5, earnings increased 2.64 times and 2.29 times in 2015 in the two scenarios. Pipeline separation resulted in a more significant increase. In 2010, the Henan section of No. 2 West-East Gas Pipeline had not yet been constructed. Therefore, Sanmenxia, Lushan and Nanyang exhibit an absence of consumption surplus. The same conclusions can be drawn from both scenarios. The top three cities in terms of consumer surplus were Xuedian, Huaiyang and Qingfeng in 2010 and Xuedian, Huaiyang and Boai in 2015, with the top two unchanged. A city in the vicinity of Zhengzhou in Henan Province, Xuedian, consumes substantially more gas than other areas. During the period 2010-2015, a shift of the gas-using hot spot from Puyang in southeast Henan to Boai in northwest Henan occurred. During market integration, the difference in the consumer prices of each city could be

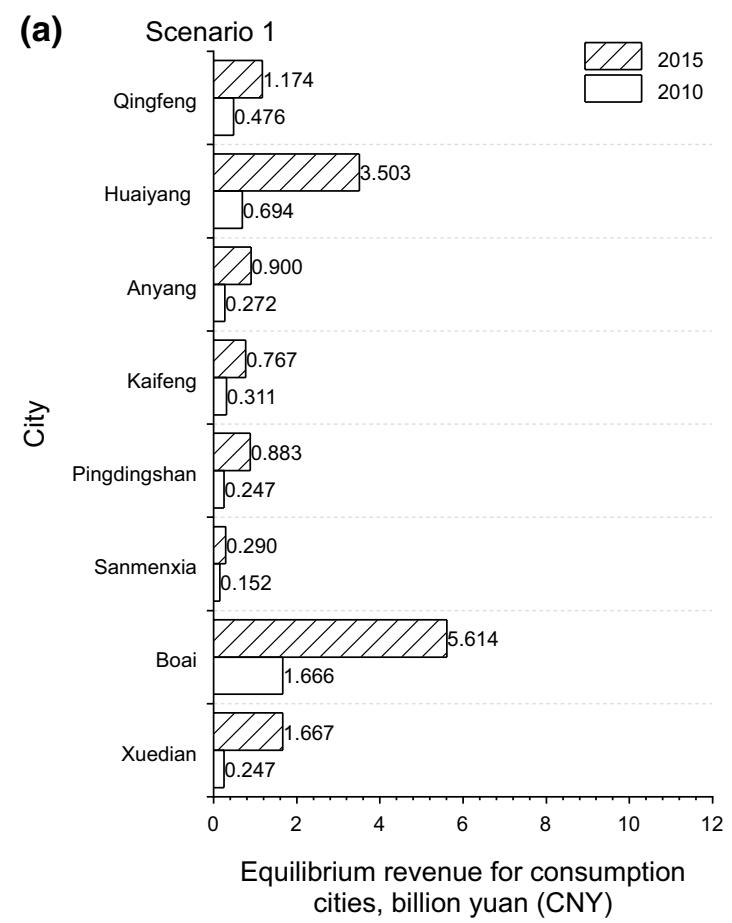

attributed to the difference in transportation fees. Obviously, pipeline separation increased competition by decreasing to a certain degree the difference in transportation fees caused by the diversification of suppliers, resulting in lower enduser prices for natural gas. Therefore, the earnings for the downstream market in scenario 2 are higher than those in scenario 1.

As shown in Fig. 6, the overall social welfare of scenario 1 in 2010 was 9.4612 billion yuan (CNY), and the overall social welfare of scenario 2 was 14.9806 billion yuan (CNY), which was 1.59 times the former. The overall social welfare of scenario 1 in 2015 was 38.4384 billion yuan (CNY), and the overall social welfare of scenario 2 was 64.7513 billion yuan (CNY), which was 1.68 times the former. Pipeline separation causes social welfare shifts from upstream to downstream, and the increase in social welfare in the midstream and downstream is larger than the loss of social welfare in the upstream. In addition, with the expansion of the scale of the market, third-party access to social benefits increases.

The upstream and midstream are monopolized by CNPC, Sinopec and CNOOC, who use their respective pipeline networks for gas transmission. This arrangement limits consumers with respect to selecting the most reasonable gas source. Monopoly companies acquire the social benefits of downstream users. China's natural gas prices are regulated by the National Development and Reform Commission, and distortions in demand and supply result in welfare losses.

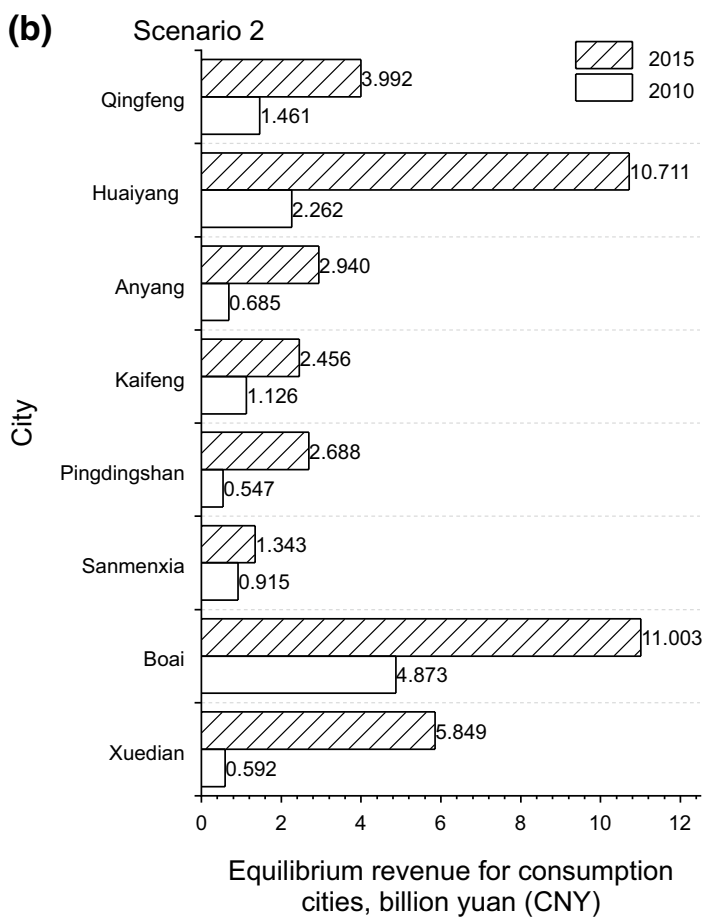

Fig. 5 Consumer earnings 


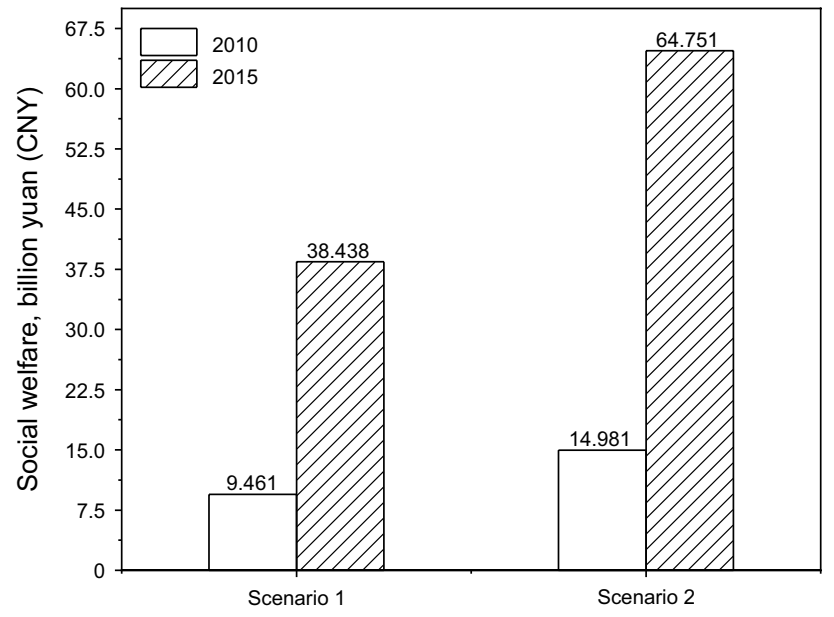

Fig. 6 Overall social welfare in 2010 and 2015

The pipeline integration of the natural gas market together with government restrictions on gas prices fixes overall social welfare at a low level. Direct trading between certain producers and consumers becomes a reality with the introduction of a third party. As production and consumption are stimulated in such a market-driven mode, overall social welfare increases. As demonstrated by the presented evidence, competition between gas sources intensifies when rational allocation occurs after pipeline separation, eliminating price discrimination, improving resource utilization and increasing social welfare.

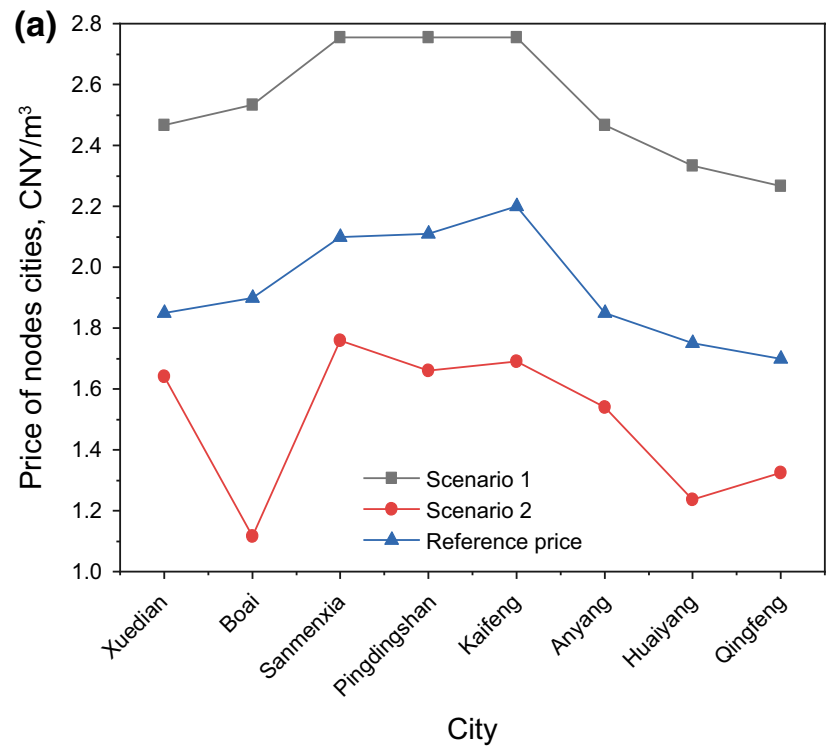

\subsubsection{Prices}

Figure 7 presents the equilibrium prices in the downstream market for selected cities and for each simulation scenario. As can be observed, the equilibrium gas price is more stable in scenario 1, with an integrated pipeline. When pipelines are divided, as in scenario 2 , the equilibrium prices of consumption reduce. In 2010, when there was pipeline separation, prices in gas-distributing cities decreased by at least one unit. In 2015, in the same scenario, gate prices in the cities (excluding Sanmenxia, which experienced a relatively smaller decrease) decreased by two units. Pipeline separation is confirmed to provide the downstream gas-distributing cities more supplier options, thus accounting for the general trend of price decline. For consumers, pipeline separation means lower gas prices.

\section{Conclusions}

This paper presents a mixed complementarity model of the regional natural gas market in China and analyzes the welfare changes of multiple market players along the natural gas chain. We used CNGASMOD for the numerical simulations with reference data for the base years 2010 and 2015. Through the modeling of the natural gas market in Henan Province, this paper analyzes the welfare changes of market players (i.e., producers, distributors and consumers) along the industrial chain of natural gas in two scenarios: the demand price elasticity of the downstream market and the equilibrium price of natural gas.

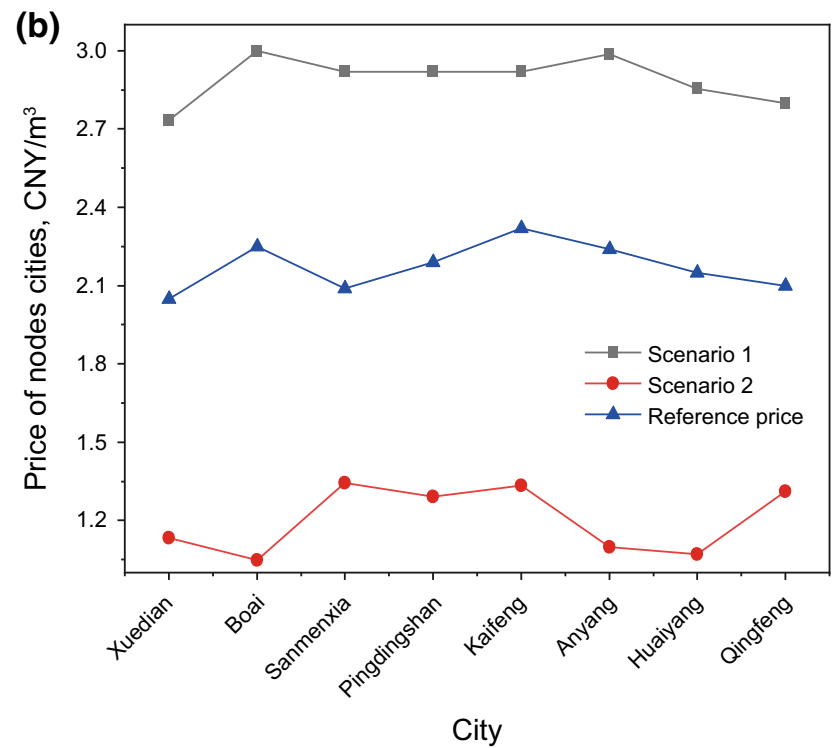

Fig. 7 Consumer prices of nodes (in a 2010, b 2015). Note: The reference price for natural gas is the real price in each year. The prices in Scenarios 1 and 2 are the equilibrium prices of consumption 
We observe that gas prices tend to be lower with unbundling than with ownership integration. The quantities are larger and prices lower in the scenarios with pipeline separation compared with the pipeline integration scenario. This result translates into higher welfare, which has critical implications for the market organization of China's natural gas sector.

There are three conclusions as follows: (1) Pipeline separation yields greater overall social welfare than pipeline integration, with the welfare shifting from oil-gas producers to consumption markets. (2) Pipeline separation lowers equilibrium consumption prices by driving competition among gas supply sources. It was found that for a consumer city at the pipeline network connection point, the revenue growth rate is faster than for other consumer cities because it can more easily choose natural gas from different supplies. (3) Pipeline separation increases the contribution of natural gas to primary energy. Consumers can obtain natural gas at a lower price in the pipeline separation scenario, which encourages increased natural gas consumption.

Experience in OECD countries indicates that without effective pipeline separation, reforms typically fail to achieve their targets. Thus, pipeline separation has been an essential condition for effective wholesale pricing reform and to provide the necessary incentives for domestic production and competition. In 2016, the CNDRC issued measures for the administration of natural gas pipeline transmission pricing, which should encourage natural gas transmission companies to open their pipeline capacity to third-party companies, thereby increasing utilization and achieving excess return. In addition, effective separation of the management and accounting of natural monopolies, as well as gas supply and trading, are crucial to ensuring pipeline separation and efficient regulation.

Acknowledgements The authors gratefully acknowledge the support provided by the National Natural Science Foundation of China under Grant Nos. 71673257 and 71804167.

Open Access This article is distributed under the terms of the Creative Commons Attribution 4.0 International License (http://creativeco mmons.org/licenses/by/4.0/), which permits unrestricted use, distribution, and reproduction in any medium, provided you give appropriate credit to the original author(s) and the source, provide a link to the Creative Commons license, and indicate if changes were made.

\section{References}

Boots MG, Rijkers FAM, Hobbs BF. Trading in the downstream European gas market: a successive oligopoly approach. Energy J. 2004;25:73-102. https://doi.org/10.2307/41323043.

China National Development and Reform Commission. Notice on printing and distributing the medium and long-term oil and gas pipeline network plan. 2017. http://www.ndrc.gov.cn/zcfb/zcfbt z/201707/t20170712_854363.html (in Chinese). Accessed 19 May 2017.

China National Energy Administration. Energy development strategy action plan (2014-2020). National Energy Administration of China. 2014. http://www.nea.gov.cn/2014-12/03/c_133830458. htm (in Chinese). Accessed 3 Dec 2014.

David L, Percebois J. Access pricing on gas networks and capacity release markets: lessons from North American and European experiences. Energy Stud Rev. 2004;12:125-42. https://doi. org/10.15173/esr.v12i2.456.

Devine MT, Gabriel SA, Moryadee S. A rolling horizon approach for stochastic mixed complementarity problems with endogenous learning: application to natural gas markets. Comput Oper Res. 2016;68:1-15. https://doi.org/10.1016/j.cor.2015.10.013.

Dong J, Sha S, Li X, et al. Ownership unbundling of natural gas transmission networks in China. J Clean Prod. 2018;195:14553. https://doi.org/10.1016/j.jclepro.2018.05.173.

Egging RG, Gabriel SA. Examining market power in the European natural gas market. Energy Policy. 2006;34:2762-78. https:// doi.org/10.1016/j.enpol.2005.04.018.

Egging R, Holz F, Gabriel SA. The world gas model: a multi-period mixed complementarity model for the global natural gas market. Energy. 2010;35:4016-29. https://doi.org/10.1016/j.energ y.2010.03.053.

Egging R, Holz F. Risks in global natural gas markets: investment, hedging and trade. Energy Policy. 2016;94:468-79. https://doi. org/10.1016/j.enpol.2016.02.016.

Electronics and Telecommunications Research Institute. Development report of oil and gas industry at home and abroad. Beijing: Petroleum Industry Press; 2018.

Gabriel SA, Kydes AS, Whitman P. The national energy modeling system: a large-scale energy-economic equilibrium model. Oper Res. 2001;49:14-25. https://doi.org/10.1287/ opre.49.1.14.11195.

Gabriel SA, Kiet S, Zhuang J. A mixed complementarity-based equilibrium model of natural gas markets. Oper Res. 2005;53:799_ 818. https://doi.org/10.1287/opre.1040.0199.

Gabriel SA, Zhuang J, Egging R. Solving stochastic complementarity problems in energy market modeling using scenario reduction. Eur J Oper Res. 2009;197:1028-40. https://doi.org/10.1016/j. ejor.2007.12.046.

Golombek R, Gjelsvik E, Rosendahl KE. Effects of liberalizing the natural gas markets in Western Europe. Energy J. 1995;16:85111. https://doi.org/10.5547/ISSN0195-6574-EJ-Vol16-No1-6.

Growitsch C, Hecking H, Panke T. Supply disruptions and regional price effects in a spatial oligopoly-an application to the Global Gas Market. Rev Int Econ 2014;22:944-75. https://doi. org/10.1111/roie.12138.

Hallack M, Vazquez M. Who decides the rules for network use? A 'common pool' analysis of gas network regulation. J Inst Econ. 2014;10:493-512. https://doi.org/10.1017/S1744137414000071.

Hecking H, Panke T. COLUMBUS: a global gas market model. EWI working paper. 2012. http://hdl.handle.net/10419/74405. Accessed 6 Dec 2012.

Holz F, Hirschhausen CV, Kemfert C. A strategic model of European gas supply (GASMOD). Energy Econ. 2008;30:766-88. https:// doi.org/10.1016/j.eneco.2007.01.018.

Laffont JJ, Tirole J. Access pricing and competition. Eur Econ Rev. 1994;38:1673-710. https://doi.org/10.1016/0014-2921(94)90046 $-9$.

Lewis D. A bundle of woe. Power Eng. 2007;21:22-5. https://doi. org/10.1049/pe:20070403.

O'Neill RP, Williard M, Wilkins B, et al. A mathematical programming model for allocation of natural gas. Oper Res. 1979;27:857-73. https://doi.org/10.1287/opre.27.5.857. 
Perner J, Seeliger A. Prospects of gas supplies to the European market until 2030 - results from the simulation model EUGAS. Util Policy. 2004;12:291-302. https://doi.org/10.1016/j.jup.2004.04.014.

Stoner M. Steady-state analysis of gas production. Transmission and distribution systems. Paper SPE. 1969.

Vazquez M, Hallack M, Glachant JM. Designing the European gas market: more liquid and less natural? Econ Energy Environ Policy. 2012;1:25-38. https://doi.org/10.5547/2160-5890.1.3.3.

Xu J, Hallack M, Vazquez M. Applying a third party access model for China's gas pipeline network: an independent pipeline operator and congestion rent transfer. J Regul Econ. 2017;51:72-97. https ://doi.org/10.1007/s11149-017-9316-Z.

Zwart GTJ. European natural gas markets: resource constraints and market power. Energy J. 2009;30:151-65. https://doi.org/10.5547/ ISSN0195-6574-EJ-Vol30-NoSI-10.

Zwart G, Mulder M. NATGAS: a model of the European natural gas market. CPB Netherlands Bureau for Economic Policy Analysis. 2006. 